\title{
Plasma Levels of Bactericidal/Permeability- Increasing Protein Correlate with Systemic Inflammation in Acute Coronary Syndrome
}

\section{Shicheng Yu}

Lu'an Hospital of Anhui Medical University https://orcid.org/0000-0002-2749-4130

\section{Zheng Li}

The First Affiliated Hospital of Bengbu Medical College

\section{Miaonan Li}

The First Affiliated Hospital of Bengbu Medical College

\section{Pan Xu}

Lu'an Hospital of Anhui Mecical University

\section{Nana Zhang}

The First Affiliated Hospital of Bengbu Medical College

Yuan Tian

Lu'an Hospital of Anhui Medical University

\section{Fudong Qian}

Lu'an Hospital of Anhui Medical University

Hongju Wang ( $\square$ hongjuwang2@sina.com )

The First Affiliated Hospital of Bengbu Medical College

\section{Research}

Keywords: Bactericidal/permeability-increasing protein (BPI), Acute coronary syndrome (ACS), Myeloperoxidase-DNA (MPO-DNA), High sensitivity C-reactive protein (hs-CRP)

Posted Date: October 5th, 2021

DOI: https://doi.org/10.21203/rs.3.rs-948455/v1

License: (c) (i) This work is licensed under a Creative Commons Attribution 4.0 International License. Read Full License 


\section{Abstract}

Background: Neutrophils play important roles in atherosclerosis and atherothrombosis. Bactericidal/permeability-increasing protein (BPI) is mainly expressed in the granules of human neutrophils in response to inflammatory stress. This observational, cross-sectional study investigated the plasma level of BPI in patients with acute coronary syndrome (ACS) and its correlation with blood neutrophil counts and circulating inflammatory biomarkers.

Methods: A total of 367 patients who had acute chest pain and who were admitted to our hospital for coronary angiography (CAG) and/or percutaneous coronary intervention (PCI) from May 1, 2020 to August 31, 2020 were recruited. Among them, 256 had a cardiac troponin value above the 99 th percentile upper reference limit and were diagnosed with ACS. The remaining patients $(n=111)$ were classified as non-ACS. The TIMI and GRACE scores were calculated at admission. The Gensini score based on CAG was used to determine atherosclerotic burden. Plasma levels of interleukin (IL)-1 $\beta$, myeloperoxidase-DNA (MPO-DNA), high sensitivity C-reactive protein (hs-CRP), S100A8/A9, and BPI were measured using enzyme-linked immunosorbent assays. Correlations of plasma BPI levels with examination scores and levels of circulating inflammatory biomarkers were explored. Receiver operating characteristic (ROC) curve analysis was used to determine the diagnostic efficacy of BPI for ACS and myocardial infarction.

Results: Patients in the ACS group showed significantly higher plasma BPI levels compared to the nonACS group (46.42 \pm 16.61 vs. $16.23 \pm 13.19 \mathrm{ng} / \mathrm{mL}, p<0.05)$. Plasma levels of IL-1 $\beta$, MPO-DNA, hs-CRP, and S100A8/A9 in the ACS group were also significantly higher than those in the non-ACS group (all $p<$ 0.05). In addition, plasma BPI levels were positively correlated with the TIMI, GRACE, and Gensini scores ( $r$ $=0.176, p=0.003 ; r=0.320, p<0.001 ; r=0.263, p<0.001$, respectively) in patients with ACS. Plasma BPI levels were also positively correlated with blood neutrophil counts $(r=0.266, p<0.001)$ and levels of circulating inflammatory biomarkers (IL-1 $\beta, r=0.512$; MPO-DNA, $r=0.452$; hs-CRP, $r=0.554$; S100A8/A9, $r$ $=0.434$; all $p<0.001)$ in patients with ACS. ROC curve analysis revealed that the diagnostic efficacy of BPI for ACS was not inferior to that of IL-1 $\beta$, MPO-DNA, hs-CRP, S100A8/A9, or blood neutrophil counts. ROC analysis also showed that the diagnostic efficacy of BPI for myocardial infarction was not inferior to that of creatine kinase (CK)-MB or cardiac troponin I.

Conclusion: BPI is associated with systemic inflammation in ACS and may be involved in the process of atherosclerosis and atherothrombosis. The potential of BPI as a prognostic and diagnostic biomarker for ACS should be investigated in clinical settings.

\section{Introduction}

Advances in the sensitivity and precision of the cardiac troponin assay in recent years has improved the diagnostic accuracy of acute chest pain [1,2]. However, a considerable proportion of patients fall in an ambiguous category due to myocardial injury or the absence of coronary plaque rupture/erosion/dissection following coronary angiography (CAG) [2, 3]. Thus, identification of novel 
biomarkers for differentiating these indeterminate patients is of great importance for the early diagnosis of acute coronary syndrome (ACS).

ACS is associated with unstable coronary atherosclerotic plaques (i.e. plaques with rupture and erosion), which may indicate exacerbation of vascular inflammation in both adaptive and innate immunity $[4,5]$. Exacerbated inflammation induces the recruitment of immune cells including mast cells, eosinophils, macrophages, and neutrophils, to the coronary vasculature [6]. Neutrophils play important roles in atherosclerosis and atherothrombosis by releasing antimicrobial proteins (e.g. S100A8/A9) [7, 8] and inflammatory mediators [e.g. interleukin (IL)-1ß] [9-11], or forming web-like structures named neutrophil extracellular traps (NETs) $[12,13]$. S100A8/A9 is a heterodimeric protein complex mainly secreted by activated neutrophils [14-17]. Myeloperoxidase-DNA (MPO-DNA) is a circulating marker of NETs $[18,19]$. The roles of these circulating inflammatory biomarkers in ACS have been explored in recent years.

Bactericidal/permeability-increasing protein (BPI) is a pluripotent protein ( $\sim 5 \mathrm{kDa})$ mainly expressed in the granules of human neutrophils in response to inflammatory stress. BPI plays a key role in the host defense against Gram-negative bacteria [20,21]. In addition to its bactericidal activity, BPI has been identified as a target of anti-neutrophil cytoplasmic antibody (ANCA) in a variety of diseases, such as cystic fibrosis [22], inflammatory bowel disease (IBD) [23, 24], reactive arthritis [25], chronic obstructive pulmonary disease (COPD) $[26,27]$, and vasculitis [28, 29]. BPI participates in lipid metabolism as its structure is similar to some lipid metabolic proteins [30]. It is also closely related to diabetes, an independent risk factor of atherosclerotic disease. A previous study revealed that plasma BPI levels were significantly associated with insulin sensitivity, glucose metabolism, central obesity, and components of metabolic syndrome in patients with glucose intolerance [31]. It was also found that plasma BPI concentrations positively correlated with levels of high-density lipoprotein cholesterol (HDL-C), total cholesterol (TC), and low-density lipoprotein cholesterol (LDL-C), as well as endothelium-dependent vasodilatation [32]. A proteomics study reported that the BPI level was markedly decreased in patients with total coronary atherosclerotic occlusion, indicating that BPI may be a biomarker for severe atherosclerotic coronary stenosis [33]. BPI has also been shown to inhibit angiogenesis by promoting apoptosis of vascular endothelial cells both in vitro and in vivo [34]. Angiogenesis is an important event in the pathogenesis of coronary heart disease (CHD), especially myocardial infarction (MI). BPI may be a prognostic marker and a therapeutic target of $\mathrm{CHD}$.

Based on the evidence in previous literature, we hypothesized that BPI may play a regulatory role in atherosclerosis-related inflammatory responses and atherothrombosis. In the present observational study, we first confirmed the inflammatory characteristics of BPI by determining if plasma BPI levels correlated with levels of hs-CRP, IL-1 $\beta$, MPO-DNA, and S100A8/A9 in patients with ACS. We then evaluated the association between plasma BPI levels and coronary atherosclerotic burden using the Gensini score. Lastly, we compared the diagnostic efficacy of BPI with other circulating inflammatory biomarkers for ACS and $\mathrm{MI}$, and determined the prognostic value of BPI based on the TIMI and GRACE scores. The findings presented here highlight the potential of BPI as a diagnostic and prognostic marker for ACS. 


\section{Materials And Methods \\ Study population}

Subjects who had acute chest pain and were clinically suspected of having ACS and who were admitted to our hospital for coronary angiography (CAG) and/or percutaneous coronary intervention (PCl) between May 1, 2020, and August 31, 2020 were screened. Patients who had one of the following characteristics were excluded: cardiogenic shock, acute infection, blood disorders, severe hepatic, or severe renal failure (plasma creatine level $>3 \mathrm{mg} / \mathrm{dl}$ ), as well as ongoing chronic inflammatory, autoimmune, or malignant diseases. Patients who had acute chest pain and a cardiac troponin I value above the 99th percentile upper reference limit were classified as ACS. The remaining patients were classified as non-ACS. The diagnosis of MI was in accordance with the criteria of the ESC/ACCF/AHA/WHF Fourth Universal Definition of Myocardial Infarction (2018) [35]. All patients had clinical indications for CAG. Intravascular ultrasound (IVUS) was used to identify coronary plaque rupture/erosion/dissection in ACS or non-ACS patients whose cardiac troponin I values were above the 99th percentile upper reference limit in the following test. In total, 256 ACS patients and 111 non-ACS patients were included in this study. All patients ranged in age between 30 and 87 years. Among the ACS patients, 159 were diagnosed with MI based on the CAG results, dynamic changes in cardiac troponin I levels, and the IVUS results. Their demographic and clinical records (i.e. age, gender, BMI, smoking history, hyperlipidemia, diabetes mellitus, atrial fibrillation, hypertension, stroke, and medications), as well as biochemical and hematological data (i.e. glucose, creatinine, uric acid, lipid profile, creatine kinase isoenzyme, platelets, neutrophils, leukocytes, etc.), were recorded for statistical analysis. BMI was calculated as weight $(\mathrm{kg})$ divided by height $(\mathrm{cm})$ in squared meters. This study was approved by the Ethics Committee of The First Affiliated Hospital of Bengbu Medical College (Bengbu, China). All participants gave written informed consent.

\section{CAG and assessment of the severity of coronary atherosclerotic burden}

CAG was performed by experienced cardiologists according to the conventional Judkins method. Rapamycin-coated stents and radial artery puncture were used for all patients. During the procedure, $1 \mathrm{~mL}$ of $1 \%$ lidocaine was used for local anesthesia. After the artery sheath was implanted, 3,000 U heparin and $200 \mu \mathrm{g}$ nitroglycerin were injected through the sheath. The CAG results were interpreted by experienced physicians following current guidelines [36]. The decision regarding subsequent performance of $\mathrm{PCl}$ was made by the same physicians according to current PCl guidelines [36].

Periprocedural medication and management were administered in accordance with current PCl guidelines [37]. Dual antiplatelet therapies and statins were administered to all patients before the procedure. The criteria for successful PCI were in accordance with international practice guidelines: TIMI grade 3 blood flow and residual stenosis $\leq 20 \%$ after the procedure. The Gensini score was used to quantitatively assess the severity of coronary atherosclerotic burden according to the distributions and degree of stenosis shown in CAG [38]. 


\section{Blood Samples}

Blood samples $(5 \mathrm{~mL})$ were collected from each subject through the median cubital vein and tested within 30 mins after admission. These samples were collected in tubes with heparin sodium or EDTA. Samples with heparin sodium were used for a series of blood tests following a standard protocol from the Department of Clinical Laboratory at our hospital, which included routine blood analysis, blood glucose, coagulation function, lipid profile, uric acid, renal function, creatine kinase isoenzyme, and cardiac troponin I. Plasma samples were collected by centrifugation at $2,500 \times \mathrm{g}$ for $15 \mathrm{~min}$ and stored at $-80^{\circ} \mathrm{C}$ until subsequent analysis. Additional morning fasting blood samples were collected within $24 \mathrm{~h}$ of admission for monitoring fasting blood glucose, creatine kinase isoenzyme, and cardiac troponin I.

\section{Enzyme-linked Immunosorbent Assay (Elisa)}

The MPO-bound DNA complexes in plasma samples were detected using ELISA as previously described [39-41]. Briefly, a 96-well microtiter plate (Corning) was coated with anti-MPO antibody $(4 \mu \mathrm{g} / \mathrm{mL}$, BioRad) at $4^{\circ} \mathrm{C}$ overnight, followed by 2 -h incubation with $1 \%$ bovine plasma albumin in phosphate buffered saline (PBS) at room temperature. Plasma samples were added to the plate and incubated overnight at $4^{\circ} \mathrm{C}$. For detection, anti-dsDNA-HRP antibody (1:100 dilution, Roche Diagnostic) was added to the samples and incubated at room temperature for $2 \mathrm{~h}$. The reaction was developed with 3,3',5,5'tetramethylbenzidine (BD Biosciences) and terminated by the addition of $2 \mathrm{~N}$ sulfuric acid. Absorbance was detected at $450 \mathrm{~nm}$ using a plate reader (Synergy, BioTek). The plasma levels of BPI, S100A8/A9, hsCRP, and IL-1 $\beta$ were also measured using ELISA kits according to the manufacturer's instructions (Cusabio Biotech, China). The absorbance was read at $450 \mathrm{~nm}$ in a microplate reader. The means were used to calculate the levels of BPI, S100A8/A9, hs-CRP, and IL-1 $\beta$ in corresponding samples based on established standard curves. ELISA experiments were performed in triplicate.

\section{Statistical analysis}

Numerical data are shown as means \pm standard deviation (SD). Student's $t$-test or one-way analysis of variance followed by Bonferroni test was used to determine statistical significance. Pearson's or Spearman's correlation analysis was used to determine the correlation between parameters. Linear regression analysis was performed to identify independent influencing factors of BPI. A $p$-value $<0.05$ was considered statistically significant. Receiver operating characteristic (ROC) curve analysis was used to evaluate the diagnostic efficacy of plasma BPI levels for ACS and MI. All data analyses were performed using SPSS 22.0 software (IBM Corp.).

\section{Results}

\section{Demographic and clinical characteristics of participants at baseline}


There were no significant differences in age, gender, BMI, smoking history, hypercholesterolemia, diabetes mellitus, atrial fibrillation, stroke, hypertension, and medications between the ACS and non-ACS groups (Table 1). 
Table 1

Clinical characteristics of the study population.

\begin{tabular}{|c|c|c|}
\hline & non-ACS & ACS \\
\hline & $(n=111)$ & $(n=256)$ \\
\hline \multicolumn{3}{|l|}{ Medical history } \\
\hline Age, years & $60.63 \pm 10.74$ & $61.88 \pm 11.21$ \\
\hline Male sex, n (\%) & $68(61.26)$ & $178(69.53)$ \\
\hline Heart rate, bpm & $70.98 \pm 8.92$ & $72.72 \pm 11.87$ \\
\hline Systolic pressure, mmHg & $131.87 \pm 15.93$ & $134.07 \pm 19.29$ \\
\hline $\mathrm{BMI}, \mathrm{kg} / \mathrm{m} 2$ & $24.83 \pm 3.80$ & $24.88 \pm 3.54$ \\
\hline Smoker, n (\%) & 19(17.12) & $50(19.53)$ \\
\hline Hypertension, n (\%) & $62(55.86)$ & $138(53.91)$ \\
\hline Hyperlipidemia, n (\%) & $35(31.53)$ & $65(25.39)$ \\
\hline Diabetes mellitus, n (\%) & $15(13.51)$ & $46(17.97)$ \\
\hline Atrial fibrillation, n (\%) & $2(1.80)$ & $5(1.95)$ \\
\hline Stroke, n (\%) & $6(5.41)$ & $15(5.86)$ \\
\hline \multicolumn{3}{|l|}{ Medication } \\
\hline Antiplatelet, n (\%) & 101(90.99) & $244(95.31)$ \\
\hline Anticoagulant, $\mathrm{n}(\%)$ & $61(54.95)$ & 196(76.56) \\
\hline Lipid-lowering agent, n (\%) & $98(88.29)$ & $232(90.63)$ \\
\hline ACE inhibitor/ARB, n (\%) & $35(31.53)$ & $107(41.80)$ \\
\hline$\beta$-blockers, n (\%) & $49(44.14)$ & $155(60.55)$ \\
\hline Nitrate esters, n (\%) & $35(31.53)$ & $125(48.83)$ \\
\hline Proton pump inhibitors, $\mathrm{n}(\%)$ & $87(78.38)$ & $172(67.19)$ \\
\hline
\end{tabular}

\section{Biochemical and hematological data}

Glucose, $\mathrm{mmol} / \mathrm{L}$

Creatinine, $\mu \mathrm{mol} / \mathrm{L}$
$5.42 \pm 1.97 *$

$69.52 \pm 12.93^{*}$

$338.15 \pm 83.775$
$6.17 \pm 2.94$

$74.41 \pm 21.19$

$334.01 \pm 98.38$

Uric acid, $\mu \mathrm{mol} / \mathrm{L}$ 


\begin{tabular}{|c|c|c|}
\hline & non-ACS & ACS \\
\hline Cholesterol, $\mathrm{mmol} / \mathrm{L}$ & $4.49 \pm 3.83$ & $4.08 \pm 1.28$ \\
\hline High Density Lipoprotein, mmol/L & $1.08 \pm 0.29 *$ & $0.98 \pm 0.27$ \\
\hline Low Density Lipoprotein, mmol/L & $2.45 \pm 0.85$ & $2.37 \pm 0.89$ \\
\hline Apolipoprotein A, mmol/L & $1.20 \pm 0.29 *$ & $1.11 \pm 0.27$ \\
\hline Apolipoprotein B, mmol/L & $0.84 \pm 0.28$ & $0.81 \pm 0.29$ \\
\hline $\mathrm{LP}(\mathrm{a}), \mathrm{mmol} / \mathrm{L}$ & $334.66 \pm 267.41^{*}$ & $385.89 \pm 337.51$ \\
\hline Triglycerides, $\mathrm{mmol} / \mathrm{L}$ & $1.73 \pm 1.56$ & $2.02 \pm 2.33$ \\
\hline MB isoform of creatine kinase, IU/L & $12.81 \pm 8.20^{*}$ & $38.47 \pm 60.53$ \\
\hline Troponin I, ng/mL & $0.40 \pm 0.30 *$ & $3.43 \pm 8.83$ \\
\hline Platelets, $* 10^{\wedge} 9 / \mathrm{L}$ & $206.57 \pm 60.49$ & $210.45 \pm 69.00$ \\
\hline Leukocytes, *10^9/L & $6.42 \pm 1.76$ & $7.56 \pm 2.50$ \\
\hline Neutrophils, ${ }^{\star} 10^{\wedge} 9 / \mathrm{L}$ & $3.88 \pm 1.40^{\star}$ & $5.09 \pm 2.45$ \\
\hline Lymphocytes (\%) & $30.56 \pm 8.54^{\star}$ & $25.49 \pm 9.56$ \\
\hline Neutrophils (\%) & $59.13 \pm 9.38 *$ & $65.17 \pm 11.02$ \\
\hline Monocytes (\%) & $6.82 \pm 1.98$ & $6.71 \pm 2.10$ \\
\hline Eosinophils (\%) & $2.37 \pm 1.66$ & $2.02 \pm 2.12$ \\
\hline Basophils (\%) & $0.32 \pm 0.56$ & $0.26 \pm 0.55$ \\
\hline \multicolumn{3}{|l|}{ Data are presented as mean $\pm S D$. } \\
\hline $\begin{array}{l}\text { *p }<0.05 \text { was statistically significant } \\
\text { group. }\end{array}$ & is were made an & Ion-ACS and ACS \\
\hline
\end{tabular}


Table 2

The level of inflammation biomarkers and scores

\begin{tabular}{|c|c|c|}
\hline & non-ACS & ACS \\
\hline & $(n=111)$ & $(n=256)$ \\
\hline Plasma BPI (ng/mL) & $16.23 \pm 13.19 *$ & $46.42 \pm 16.61$ \\
\hline Hs-CRP (pg/mL) & $17699.58 \pm 16501.09 *$ & $40355.17 \pm 8389.56$ \\
\hline $\mathrm{IL}-1 \beta(p g / m L)$ & $2509.66 \pm 1680.89 *$ & $4843.68 \pm 1076.73$ \\
\hline MPO-DNA (ng/mL) & $456.39 \pm 304.33^{\star}$ & $890.63 \pm 382.67$ \\
\hline S100A8/A9 (ng/mL) & $11.74 \pm 7.61^{\star}$ & $19.54 \pm 8.71$ \\
\hline TIMI score & $1.73 \pm 1.13^{\star}$ & $3.24 \pm 1.45$ \\
\hline GRACE score & $107.41 \pm 23.84^{\star}$ & $129.10 \pm 33.47$ \\
\hline Gensini score & $21.01 \pm 32.16^{*}$ & $56.98 \pm 35.62$ \\
\hline \multicolumn{3}{|c|}{$\mathrm{BPI}$, bactericidal/permeability increasing protein } \\
\hline \multicolumn{3}{|l|}{ IL-1 $\beta$, interleukin-1 $\beta$} \\
\hline \multicolumn{3}{|c|}{ Hs-CRP, high sensitivity C-reactive protein } \\
\hline \multicolumn{3}{|c|}{ Data are presented as mean \pm SD } \\
\hline \multicolumn{3}{|c|}{$\begin{array}{l}{ }^{*}<<0.05 \text { was statistically significant when comparisons were made among the non-ACS and ACS } \\
\text { group }\end{array}$} \\
\hline
\end{tabular}

There were no significant differences in the levels of uric acid, cholesterol, LDL, apolipoprotein B, triglycerides, numbers of platelets and leukocytes, and percentages of monocytes, eosinophils, and basophils between the ACS and non-ACS groups. The level of creatinine in the non-ACS group was significantly lower than that of the ASC group (69.52 $\pm 12.93 v s .74 .41 \pm 21.19 \mu \mathrm{mol} / \mathrm{L}, p<0.05)$. Patients with ASC had significantly higher levels of glucose $(6.17 \pm 2.94 \mathrm{vs} .5 .42 \pm 1.97 \mathrm{mmol} / \mathrm{L})$ and $\mathrm{Lp}(\mathrm{a})$ $(385.89 \pm 337.51 \mathrm{vs} .334 .66 \pm 267.41 \mathrm{mmol} / \mathrm{L})$, an increased number of neutrophils $(5.09 \pm 2.45 \mathrm{vs} .3 .88$ $\pm 1.40 * 10^{\wedge} \mathrm{g} / \mathrm{L}$ ), and a higher percentage of neutrophils ( $65.17 \pm 11.02 \mathrm{vs} .59 .13 \pm 9.38$ ), but lower levels of $\mathrm{HDL}(2.37 \pm 0.89 v s .2 .45 \pm 0.85 \mathrm{mmol} / \mathrm{L})$ and apolipoprotein $\mathrm{A}(1.11 \pm 0.27 v s .1 .20 \pm 0.29 \mathrm{mmol} / \mathrm{L})$, and a lower percentage of lymphocytes $(25.49 \pm 9.56 \mathrm{vs}$. $30.56 \pm 8.54)$ compared with the non-ACS group (all $p<0.05)$ (Table 1$)$.

\section{Plasma BPI levels were significantly higher in the ACS group compared to the non-ACS group}

The ACS group showed significantly higher plasma levels of BPI compared with the non-ACS group (46.42 \pm 16.61 vs. $16.23 \pm 13.19 \mathrm{ng} / \mathrm{mL}, p<0.05)$ (Table 2, Figure 1a). 


\section{Levels of Hs-CRP, IL-1ß, MPO-DNA, and S100A8/A9 in the ACS and control groups}

Plasma levels of hs-CRP, IL-1 $\beta$, MPO-DNA, and S100A8/A9 in the ACS group were significantly higher compared with the non-ACS group (all $p<0.05$ ) (Table 2).

\section{TIMI, GRACE, and Gensini scores in the ACS and control groups}

The TIMI, GRACE, and Gensini scores of the ACS group were significantly higher compared with the nonACS group (all $p<0.05$ ) (Table 2).

\section{Correlation of plasma BPI levels with traditional risk factors and circulating inflammatory biomarkers}

To investigate the clinical relevance of high plasma BPI levels in ACS, we examined the correlations of BPI levels with 14 clinical characteristics, 15 blood parameters, four inflammation biomarkers, and five CAG indexes in ACS patients. We adjusted $p$-values using the LD-adjusted Bonferroni correction to decrease the probability of Type I errors. The significance level was set as $p<0.005$ after correction.

We found that plasma BPI levels positively correlated with the TIMI and GRACE scores $(r=0.176, p=$ $0.003 ; r=0.320, p<0.001)$ in patients with ACS, and this correlation was more significant in the whole cohort $(r=0.486, p<0.001 ; r=0.384, p<0.001)$. After correction, the correlations of plasma BPI levels with the TIMI and GRACE scores were confirmed in patients with ACS (all $p<0.001$ ) (Tables 3 and 4). 
Table 3

Spearman correlation between BPI with clinical characteristics and inflammation Biomarkers

non-ACS $(n=111) \quad$ ACS $(n=256)$

Whole Cohort $(n=367)$

\begin{tabular}{|c|c|c|c|c|c|c|}
\hline Variable & rs & p-value & rs & p-value & rs & $\mathrm{p}$-value \\
\hline \multicolumn{7}{|l|}{ Clinical characteristics } \\
\hline Age (years) & 0.06 & 0.478 & 0.039 & 0.534 & $.140^{\star \star}$ & 0.005 \\
\hline Gender $(F=1, M=0)$ & -0.151 & 0.071 & -0.005 & 0.941 & $-.177^{\star \star}$ & 0 \\
\hline Heart rate(bpm) & -0.142 & 0.092 & 0.081 & 0.194 & 0.029 & 0.56 \\
\hline Systolic pressure $(\mathrm{mmHg})$ & 0.155 & 0.065 & -0.074 & 0.237 & 0.029 & 0.56 \\
\hline $\mathrm{BMI}\left(\mathrm{kg} / \mathrm{m}^{2}\right)$ & 0.037 & 0.66 & -0.132 & 0.061 & -0.061 & 0.26 \\
\hline Hypertension & $.188^{\star}$ & 0.024 & -0.07 & 0.262 & 0.034 & 0.496 \\
\hline Hyperlipidemia & -0.124 & 0.139 & -0.033 & 0.598 & -0.026 & 0.608 \\
\hline Diabetes mellitus & -0.106 & 0.208 & -0.041 & 0.509 & 0.056 & 0.261 \\
\hline Smoking & 0.027 & 0.747 & 0.08 & 0.201 & $.113^{\star}$ & 0.024 \\
\hline Atrial fibrillation & 0.049 & 0.557 & 0.106 & 0.091 & 0.093 & 0.062 \\
\hline Stroke & -0.12 & 0.15 & 0.004 & 0.945 & 0.073 & 0.145 \\
\hline Previous stenosis $\geq 50 \%$ & $.217^{\star \star}$ & 0.009 & $-.305^{\star \star}$ & 0 & 0.017 & 0.729 \\
\hline PreMl & 0.134 & 0.11 & -0.092 & 0.143 & 0.019 & 0.707 \\
\hline PrePCl & 0.112 & 0.181 & $-.212^{\star \star}$ & 0.001 & 0.025 & 0.62 \\
\hline TIMI score & $.194^{\star}$ & 0.02 & $.176 \star \star$ & 0.003 & $.486^{\star \star}$ & 0 \\
\hline Grace score & -0.135 & 0.108 & $.320 \star \star$ & 0 & $.384^{\star \star}$ & 0 \\
\hline \multicolumn{7}{|l|}{ Blood parameters } \\
\hline Blood neutrophils counts & -0.001 & 0.986 & $.266^{\star \star}$ & 0.000 & $.316^{\star \star}$ & 0 \\
\hline Blood leukocytes counts & -0.043 & 0.607 & -0.1 & 0.12 & $-.111^{\star}$ & 0.029 \\
\hline Neutrophils (\%) & 0.006 & 0.947 & $.263^{\star \star}$ & 0 & $.290 \star \star$ & 0 \\
\hline Blood platelets counts & -0.147 & 0.08 & 0.024 & 0.706 & -0.056 & 0.268 \\
\hline Glucose(mmol/L) & -0.077 & 0.362 & $.138^{*}$ & 0.027 & $.135^{\star \star}$ & 0.007 \\
\hline Cholesterol(mmol/L) & -0.06 & 0.477 & 0.116 & 0.075 & 0.004 & 0.944 \\
\hline Triglycerides(mmol/L) & 0.061 & 0.473 & -0.084 & 0.2 & 0.004 & 0.937 \\
\hline
\end{tabular}




\begin{tabular}{|c|c|c|c|c|c|c|}
\hline \multirow[b]{2}{*}{$\mathrm{HDL}(\mathrm{mmol} / \mathrm{L})$} & \multicolumn{2}{|c|}{ non-ACS $(n=111)$} & \multicolumn{2}{|c|}{$\operatorname{ACS}(n=256)$} & \multicolumn{2}{|c|}{ Whole Cohort $(n=367)$} \\
\hline & 0.044 & 0.603 & -0.002 & 0.971 & $-.114^{\star}$ & 0.027 \\
\hline LDL (mmol/L) & -0.054 & 0.524 & 0.127 & 0.051 & 0.006 & 0.907 \\
\hline Apolipoprotein A(mmol/L) & 0.03 & 0.726 & -0.018 & 0.78 & -0.097 & 0.06 \\
\hline Apolipoprotein B(mmol/L) & -0.051 & 0.547 & $.137^{\star}$ & 0.036 & 0.01 & 0.843 \\
\hline LP (a)(mmol/L) & $.293^{\star \star}$ & 0.002 & -0.049 & 0.517 & $.117^{\star}$ & 0.048 \\
\hline CK-MB (IU/L) & -0.021 & 0.829 & $.208^{\star *}$ & 0.002 & $.268 * *$ & 0 \\
\hline Creatinine $(\mu \mathrm{mol} / \mathrm{L})$ & $.182^{\star}$ & 0.029 & -0.094 & 0.136 & 0.092 & 0.065 \\
\hline Uric $\operatorname{acid}(\mu \mathrm{mol} / \mathrm{L})$ & 0.119 & 0.158 & 0.021 & 0.742 & 0.058 & 0.248 \\
\hline \multicolumn{7}{|l|}{ New biomarkers } \\
\hline Hs-CRP (pg/mL) & $.700^{\star \star}$ & 0 & $.554^{\star \star}$ & 0.000 & $.746 * \star$ & 0 \\
\hline $\mathrm{IL}-1 \beta(\mathrm{pg} / \mathrm{mL})$ & $.638^{\star \star}$ & 0 & $.512^{\star \star}$ & 0.000 & $.741^{\star \star}$ & 0 \\
\hline MPO-DNA (ng/mL) & $.403^{\star \star}$ & 0 & $.452^{\star \star}$ & 0.000 & $.611^{\star *}$ & 0 \\
\hline $\mathrm{S} 100 \mathrm{~A} 8 / \mathrm{A} 9(\mathrm{ng} / \mathrm{mL})$ & $.211^{\star}$ & 0.011 & $.434^{\star \star}$ & 0.000 & $.529 * \star$ & 0 \\
\hline \multicolumn{7}{|l|}{ Coronary angiography } \\
\hline Number of diseased vessels & $.665^{\star \star}$ & 0 & 0.047 & 0.450 & $.489 * *$ & 0 \\
\hline Calcified lesions & 0.122 & 0.144 & 0.048 & 0.440 & $.128^{\star}$ & 0.011 \\
\hline Chronic total occlusion & $.258^{\star \star}$ & 0.002 & 0.111 & 0.077 & $.264^{\star \star}$ & 0 \\
\hline In-stent restenosis & $.305^{\star \star}$ & 0 & $-.173^{\star \star}$ & 0.005 & 0.043 & 0.397 \\
\hline Total number of stents & 0.111 & 0.184 & -0.059 & 0.347 & $.277^{\star *}$ & 0 \\
\hline Gensini score & $.701^{\star \star}$ & 0 & $.263^{\star \star}$ & 0.000 & $.605^{\star *}$ & 0 \\
\hline \multicolumn{7}{|c|}{ ACS, acute coronary syndrome. HDL, high density lipoprotein. LDL, low density lipoprotein. } \\
\hline \multicolumn{7}{|c|}{ CK-MB, MB isoform of creatine kinase. BMI, body mass index } \\
\hline \multicolumn{7}{|c|}{ BPI, bactericidal/permeability increasing protein } \\
\hline \multicolumn{7}{|c|}{ Hs-CRP, high sensitivity C-reactive protein } \\
\hline \multicolumn{7}{|l|}{ IL-1 $\beta$, interleukin-1 $\beta$} \\
\hline \multicolumn{7}{|c|}{ ** Correlation was statistically significant at 0.01 level (Two-tailed). } \\
\hline * Correlation was statistically & gnifican & at $0.05 \mathrm{le}$ & (Two-te & & & \\
\hline
\end{tabular}


Table 4

Unary linear regression of BPI

\begin{tabular}{|c|c|c|c|c|c|}
\hline Index & B & S.E. & Beta & $\mathbf{T}$ & $\mathbf{p}$ \\
\hline $\mathrm{Hs}-\mathrm{CRP}(\mathrm{pg} / \mathrm{mL})$ * & 0.001 & 0 & 0.778 & 24.744 & 0 \\
\hline $\mathrm{IL}-1 \beta(\mathrm{pg} / \mathrm{mL})$ * & 0.009 & 0 & 0.767 & 23.86 & 0 \\
\hline MPO-DNA (ng/mL) * & 0.032 & 0.002 & 0.627 & 16.046 & 0 \\
\hline S100A8/A9 $(\mathrm{ng} / \mathrm{mL})$ * & 1.264 & 0.098 & 0.543 & 12.893 & 0 \\
\hline Neutrophils $\left(* 10^{\wedge} 9 / L\right) *$ & 3.392 & 0.459 & 0.353 & 7.385 & 0 \\
\hline Platelets (*10^9/L) & -0.008 & 0.016 & -0.024 & -0.476 & 0.634 \\
\hline Glucose $(\mathrm{mmol} / \mathrm{L})$ * & 1.807 & 0.399 & 0.222 & 4.528 & 0 \\
\hline $\mathrm{LP}(\mathrm{a})(\mathrm{mmol} / \mathrm{L})$ & 0.007 & 0.004 & 0.113 & 1.906 & 0.058 \\
\hline Previous coronary artery disease $\geq 50 \%$ & 0.069 & 2.449 & 0.001 & 0.028 & 0.978 \\
\hline In-stent restenosis & 3.663 & 5.615 & 0.033 & 0.652 & 0.515 \\
\hline TIMI score* & 6.826 & 0.638 & 0.473 & 10.703 & 0 \\
\hline GRACE score* & 0.276 & 0.03 & 0.424 & 9.342 & 0 \\
\hline Gensini score* & 0.293 & 0.024 & 0.53 & 12.459 & 0 \\
\hline \multicolumn{6}{|c|}{ BPI, bactericidal/permeability increasing protein } \\
\hline \multicolumn{6}{|l|}{ Hs-CRP, high sensitivity C-reactive protein } \\
\hline \multicolumn{6}{|l|}{ IL-1 $\beta$, interleukin-1 $\beta$} \\
\hline$* p<0.005$ & & & & & \\
\hline
\end{tabular}

No significant correlations were found between plasma BPI levels and blood platelet counts, although recent RNA-seq data analysis reported the upregulation of BPI in the platelets of patients with STEMI/NSTEMI [42]. Plasma BPI levels positively correlated with blood neutrophil counts $(r=0.266, p<$ $0.001)$ in patients with ACS, and this correlation was more significant in the whole cohort $(r=0.316, p<$ 0.001). After correction, the correlations between plasma BPI levels and blood neutrophil counts were confirmed in patients with ACS $(p<0.001)$ (Tables 3 and 4, Figure 2).

In addition, we found that plasma BPI levels positively correlated with glucose levels $(r=0.138, p=$ $0.0027)$ in patients with ACS, and this correlation was also significant in the whole cohort $(r=0.135, p=$ 0.007). After correction, the correlations between plasma BPI levels and glucose levels were confirmed in patients with ACS $(p<0.001)$ (Tables 3 and 4$)$. 
We next examined the correlations of plasma BPI levels with the levels of hs-CRP, IL-1 $\beta, M P O-D N A$, and S100A8/A9. Plasma BPI levels positively correlated with the levels of hs-CRP, IL-1 $\beta$, MPO-DNA, and S100A8/A9 ( $r=0.746 ; r=0.741 ; r=0.611 ; r=0.529$, all $p<0.001)$ in patients with ACS (Table 3). To identify factors independently associated with BPI, we performed linear regression analysis of plasma BPI levels with the concentrations of hs-CRP, IL-1ß, MPO-DNA, and S100A8/A9 using Spearman's correlation analysis. The $p$-values were corrected using the LD-adjusted Bonferroni correction. After correction, the correlations of BPI levels with the concentrations of hs-CRP, IL-1 $\beta$, MPO-DNA, and S100A8/A9 persisted in patients with ACS (all $p<0.001$ ). These results indicate that plasma BPI levels positively correlate with the concentrations of hs-CRP, IL-1 $\beta$, MPO-DNA, and S100A8/A9 (Tables 3 and 4, Figure 3).

\section{Correlation Of Plasma Bpi Level With Cag Results}

We further investigated the correlations of BPI levels with CAG results, including "the number of diseased coronary arteries", "calcified lesions, chronic total occlusion”, "in-stent restenosis", and "total number of stents in coronary". We found that plasma BPI levels positively and significantly correlated with "the number of diseased coronary arteries", "calcified lesions, chronic total occlusion”, and "total number of stents in coronary" in the whole cohort $(r=0.489, p<0.001 ; r=0.128, p=0.011 ; r=0.264, p<0.001 ; r=$ $0.277, p<0.001)$, but not in patients with ACS. However, after LD-adjusted Bonferroni correction, the correlations of plasma BPI levels with the above indexes were not significant (Tables 3 and 4, Figure 4).

The severity of coronary atherosclerosis was assessed using the Gensini scoring system based on the CAG results. The Gensini scoring system is a well-recognized and widely used system that evaluates the severity of coronary atherosclerosis in the clinic [38, 43,44]. We also evaluated the correlation between BPI levels and the Gensini score and found that higher plasma BPI levels were associated with higher Gensini scores in patients with ACS $(r=0.263, p<0.001)$, as well as in the whole cohort $(r=0.605, p<$ 0.001 ) (Table 3). After correction, the correlation between plasma BPI levels and the Gensini score was confirmed in patients with ACS $(p<0.001)$ (Tables 3 and 4, Figure 4).

\section{ROC analysis of the diagnostic efficacy of plasma BPI levels for ACS and MI}

ROC curve analysis revealed that the optimal cut-off of plasma BPI levels for ACS was $29.01 \mathrm{ng} / \mathrm{ml}$. The ROC curves for BPI, hs-CRP, IL-1 $\beta$, MPO-DNA, S100A8/A9, and neutrophils are compared in Figures 5 and 6. We found that BPI, hs-CRP, IL-1 $\beta$, MPO-DNA, S100A8/A9, and neutrophils all had diagnostic efficacy for ACS, with area under the curve (AUC) values of $0.93(0.90-0.95), 0.87(0.84-0.91), 0.87(0.84-0.91)$, $0.81(0.76-0.85), 0.76(0.71-0.81)$, and $0.68(0.62-0.73)$, respectively. The pairwise comparison of ROC curves using the Z-Test showed that the diagnostic efficacy of BPI levels for ACS was significantly 
different from that of hs-CRP, IL-1 $\beta$, MPO-DNA, S100A8/A9, and neutrophils (BPI $v s$. hs-CRP: $z=2.856, p=$ 0.0043; BPI vs. IL-1 $\beta$ : $z=3.241, p=0.0012$; BPI vs. MPO-DNA: $z=5.316, p<0.0001 ; B P I ~ v s$. S100A8/A9: $z$ $=6.397, p<0.0001 ; \mathrm{BPI} v s$. neutrophils: $\mathrm{z}=8.186, p<0.0001)$.

Using the same method, we found that the optimal cut-off of plasma BPI levels for MI was $38.71 \mathrm{ng} / \mathrm{ml}$. The ROC curves for BPI, CK-MB, and cardiac troponin I (TnI) are compared in Figure 7. ROC curve analysis showed that BPI, CK-MB, and Tnl all demonstrated diagnostic efficacy for $\mathrm{MI}$, with AUC values of 0.88 (0.84 - 0.93), $0.71(0.64-0.79)$, and $0.83(0.78-0.89)$, respectively. Using the Z-Test, the diagnostic efficacy of BPI for MI was significantly different from that of CK-MB (BPI vs. CK-MB: $\mathrm{z}=3.896, p=$ 0.0001), but no significant difference was observed between BPI and Tnl (BPI vs. Tnl: $z=1.448, p=$ 0.1475). The above findings indicate that the diagnostic value of BPI for $\mathrm{MI}$ is not inferior to that of $\mathrm{Tnl}$, and may be superior to that of CK-MB.

\section{Discussion}

In the present study, we measured plasma BPI levels in patients with ACS and assessed their correlation with clinical characteristics and circulating inflammatory biomarkers. The major findings of this study are as follows: 1) the ACS group had significantly higher plasma BPI levels than the non-ACS group; 2 ) plasma BPI levels positively correlated with hs-CRP, IL-1 $\beta$, MPO-DNA, and S100A8/A9 levels, as well as blood neutrophil counts in patients with ACS; 3 ) plasma BPI levels positively correlated with the TIMI and GRACE scores, as well as the Gensini score, which indicated the severity of coronary atherosclerosis in patients with ACS; 4 ) the diagnostic efficacy of plasma BPI levels for ACS was not inferior to that of hsCRP, IL-1 $\beta$, MPO-DNA, S100A8/A9, and blood neutrophil counts, and also not inferior to CK-MB and TnI for the diagnosis of MI. Therefore, plasma BPI levels may serve as a biomarker for ACS.

Atherosclerosis is a chronic inflammatory disease of the vessel wall and a major cause of death worldwide. Inflammation substantially contributes to the initiation, progression, and destabilization of atherosclerosis. Although the pathogenic mechanisms underlying atherosclerosis vary across patients, neutrophils are considered the major immune cell that drives the development of this disease [45]. Neutrophils are activated in response to a variety of stimuli, such as inflammatory cytokines, and initiate subsequent effector functions. S100A8/A9 [7, 8] and IL-1 $\beta[9-11]$ are important inflammatory mediators in the process of atherosclerosis, and hs-CRP is a canonical biomarker well studied in CHD.

In the current study, we found that patients with ACS had significantly higher plasma BPI levels compared with non-ACS cases. We then sought to determine if plasma BPI levels correlated with the levels of hsCRP, IL-1 $\beta$, and S100A8/A9, as well as blood neutrophil counts. We found that plasma BPI levels 
positively correlated with the concentrations of circulating inflammatory biomarkers and blood neutrophil counts in ACS (Tables 3 and 4). These data indicate that BPI is involved in the pathogenesis of atherosclerosis, but to better understand how BPI affects atherosclerotic plaques we assessed the severity of coronary atherosclerosis in ACS using the Gensini scoring system [43]. We further examined the correlation between plasma BPI levels and the severity of coronary atherosclerosis and found that higher plasma BPI levels correlated with more severe coronary atherosclerosis in ACS, which was consistent with the results of the whole cohort. All the above findings support that BPI is an inflammatory marker involved in the pathogenesis of atherosclerosis.

Further analysis revealed that plasma BPI levels were positively correlated with the TIMI and GRACE scores $(r=0.176, p=0.003 ; r=0.320, p<0.001)$ in patients with ACS and the whole cohort $(r=0.486, p<$ $0.001 ; r=0.384, p<0.001)$, indicating that BPI was correlated with traditional risk factors and may predict the prognosis of ACS. BPI has been shown to participate in lipid metabolism $[32,46]$ owing to its lipid protein structure [47]. Plasma BPI concentrations were also positively associated with the levels of TC, LDL-C, and HDL-C [32]. It has also been suggested that BPI is related to insulin sensitivity and glucose tolerance [31]. In our study, plasma BPI levels were positively correlated with glucose levels $(r=0.138, p=$ $0.0027)$ in patients with ACS and the whole cohort $(r=0.135, p=0.007)$, which was consistent with the findings by Gubern et al. [31]. Future investigation of the causal relationship between BPI and traditional risk factors is needed.

When unstable coronary atherosclerotic plaque is accompanied by rupture/erosion in ACS or an acute coronary event, consequences may vary depending on the severity of concomitant inflammation and segmenting coronary artery thrombosis, namely, the interactions among injured endothelium, activated neutrophils, and platelets $[48,49]$. NETs are strongly implicated in thrombosis by inducing platelet activation and coagulation [50], as well as thrombus formation [51]. During inflammatory stress, NETs are released by neutrophils as structures composed of DNA fibers lined with histones and granule proteins, such as neutrophil elastase and MPO. The net-like structures have been detected in atherosclerotic lesions and arterial thrombi in humans and mice. Functionally, NETs induce the activation of endothelial cells, antigen-presenting cells, and platelets[ 52], resulting in proinflammatory immune response. Overall, these findings suggest that NETs are not only present in plaques and thrombi, but also play an important role in triggering atherosclerotic plaque formation and arterial thrombosis [53]. Previous studies have shown that MPO-DNA is a component of coronary thrombi in acute MI [54], suggesting a prothrombotic state [18], and is correlated with the prognosis of STEMI [19], severity of cardiovascular disease [55, 56], and coronary atherosclerosis [57]. S100A8/A9 is bound to NETs both in vitro and in vivo [7, 8, 58] and is implicated in the pathogenesis of MI. Increased expression of S100A8/A9 was observed in the atherosclerotic plaques of unstable angina pectoris patients $[15,59]$. In line with these findings, we found that the ACS group exhibited significantly higher levels of MPO-DNA and S100A8/A9 compared with the non-ACS group. Moreover, plasma BPI levels were positively correlated with the levels of MPO-DNA and S100A8/A9. Although MPO-DNA and S100A8/A9 play important roles in NETs formation, the role of BPI in the formation of NETs warrants further exploration. 
In recent years, advances in the sensitivity and precision of the cardiac troponin assay have improved the diagnosis of acute chest pain. However, some patients with ACS have elevated cardiac troponin levels due to myocardial injury rather than atherosclerotic plaque rupture/erosion with thrombosis. The combined used of biomarkers related to the pathogenesis of ACS and those for myocardial necrosis may contribute to the early identification of these patients for appropriate treatment. In the present study, ROC analysis showed that the diagnostic efficacy of BPI for MI was not inferior to that of CK-MB or Tnl. BPI is not a marker of myocardial necrosis, and an elevation in plasma BPI levels only indicates increased aseptic inflammation in patients with MI. Consistently, we found that BPI, hs-CRP, IL-1 $\beta$, MPO-DNA, S100A8/A9, and blood neutrophil counts all had diagnostic efficacy for ACS, and the diagnostic value of BPI for ACS was superior to that of circulating inflammatory biomarkers. Early measurement of hemostatic plasma markers in patients with ACS may provide pathophysiological information of an acute coronary event [60]. In this study, the subgroup analysis showed that plasma BPI levels were positively correlated with the hemostatic markers in MI, such as D-dimer and fibrinogen. This may be consistent with the concept that some ruptured/erosional coronary atherosclerotic plaques do not evolve into MI due to lower degrees of inflammation and thrombosis. Hence, BPI may be used to differentiate MI from myocardial injury in ACS.

Several limitations to this study should be addressed. First, this study had a relatively small sample size. Second, although we excluded patients with acute infection, ongoing chronic inflammatory, autoimmune, or malignant diseases in this observational, cross-sectional study, the increase in plasma BPI levels in patients with ACS needs to be cautiously interpreted. Finally, we did not compare BPI with other risk factors for predicting the prognosis of ACS because we did not analyze major adverse cardiovascular events during follow-up. Future studies are needed to validate our findings of BPI as a biomarker in ACS and to elucidate the mechanisms underlying BPI-induced inflammation and thrombosis.

\section{Conclusions}

In conclusion, this is the first study that assessed plasma BPI levels in patients with ACS. We showed that circulating BPI levels were increased in patients with ACS and positively correlated with blood neutrophil counts and levels of hs-CRP, IL-1 $\beta$, MPO-DNA, and S100A8/A9. ROC curve analysis shows that BPI has diagnostic value for both ACS and MI. Also, plasma BPI levels were positively correlated with the severity of coronary atherosclerosis in ACS. Therefore, BPI was associated with systemic inflammation in ACS and may be involved in NET- and neutrophil-mediated atherosclerosis and atherothrombosis. The potential role of BPI as a diagnostic and prognostic biomarker for ACS warrants further investigations.

\section{Declarations}

The authors declared that they have no conflicts of interest to this work.

\section{Funding}


This study was supported by the National Natural Science Foundation of China [81970313]; 512 Talent Cultivation Program [No. 51201317, No. 51201105]; and Major Project of Natural Science in Bengbu Medical College [Grant no. 2020byzd109].

\section{Conflict of interest}

The authors declared that they have no conflicts of interest in this work.

\section{Availability of data and material}

The datasets generated and analyzed during the present study are available from the corresponding author upon reasonable request.

\section{Authors' contributions}

SCY: Designed/performed most of the experiments and data analysis, wrote the manuscript. MNL and ZL: Sample analysis, sample measurement. PX and NNZ: Sample collection, patient data analysis, followup. YT and FDQ: Coronary angiography, study consulting. HJW: Study design, study consulting, manuscript revision. All of the authors have read and approved the manuscript.

\section{Ethics approval}

This study was approved by the Ethics Committee of The First Affiliated Hospital of Bengbu Medical College (Bengbu, China). All procedures performed in studies involving human participants were in accordance with the ethical standards of the institutional and/or national research committee and with the 1964 Helsinki Declaration and its later amendments or comparable ethical standards.

\section{Consent to participate}

All participants gave written informed consent.

\section{Consent for publication (include appropriate statements)}

Not applicable

\section{References}

1. Katus H, Ziegler A, Ekinci O, Giannitsis E, Stough WG, Achenbach S, Blankenberg S, Brueckmann M, Collinson P, Comaniciu D, et al. Early diagnosis of acute coronary syndrome. Eur Heart J. 2017;38:3049-55.

2. Clerico A, Ripoli A, Masotti S, Musetti V, Aloe R, Dipalo M, Rizzardi S, Dittadi R, Carrozza C, Storti S. Evaluation of 99th percentile and reference change values of a high-sensitivity cTnI method: A multicenter study. Clin Chim Acta. 2019;493:156-61. 
3. Clerico A, Ripoli A, Zaninotto M, Masotti S, Musetti V, Ciaccio M, Aloe R, Rizzardi S, Dittadi R, Carrozza $\mathrm{C}$, et al. Head-to-head comparison of plasma cTnl concentration values measured with three highsensitivity methods in a large Italian population of healthy volunteers and patients admitted to emergency department with acute coronary syndrome: A multi-center study. Clin Chim Acta. 2019;496:25-34.

4. Libby P, Ridker PM, Hansson GK. Inflammation in atherosclerosis: from pathophysiology to practice. J Am Coll Cardiol. 2009;54:2129-38.

5. Crea F, Libby P. Acute Coronary Syndromes: The Way Forward From Mechanisms to Precision Treatment. Circulation. 2017;136:1155-66.

6. Libby P. Inflammation in atherosclerosis. Nature 2002.

7. Wang S, Song R, Wang Z, Jing Z, Wang S, Ma J. S100A8/A9 in Inflammation. Front Immunol. 2018;9:1298.

8. Stakos DA, Kambas K, Konstantinidis T, Mitroulis I, Apostolidou E, Arelaki S, Tsironidou V, Giatromanolaki A, Skendros P, Konstantinides S, et al. Expression of functional tissue factor by neutrophil extracellular traps in culprit artery of acute myocardial infarction. Eur Heart J. 2015;36:1405-14.

9. Sutterwala FS, Haasken S, Cassel SL. Mechanism of NLRP3 inflammasome activation. Ann N Y Acad Sci. 2014;1319:82-95.

10. Baldrighi M, Mallat Z, Li X. NLRP3 inflammasome pathways in atherosclerosis. Atherosclerosis. 2017;267:127-38.

11. Tan X, Zheng X, Huang Z, Lin J, Xie C, Lin Y. Involvement of S100A8/A9-TLR4-NLRP3 Inflammasome Pathway in Contrast-Induced Acute Kidney Injury. Cell Physiol Biochem. 2017;43:209-22.

12. Soehnlein O, Steffens S, Hidalgo A, Weber C. Neutrophils as protagonists and targets in chronic inflammation. Nat Rev Immunol. 2017;17:248-61.

13. Nagareddy PR, Sreejit G, Abo-Aly M, Jaggers RM, Murphy AJ. NETosis Is Required for S100A8/A9Induced Granulopoiesis After Myocardial Infarction. Arteriosclerosis Thrombosis Vascular Biology. 2020;40:2805-7.

14. Altwegg LA, Neidhart M, Hersberger M, Müller S, Eberli FR, Corti R, Roffı M, Sütsch G, Gay S, von Eckardstein A, et al. Myeloid-related protein 8/14 complex is released by monocytes and granulocytes at the site of coronary occlusion: a novel, early, and sensitive marker of acute coronary syndromes. Eur Heart J. 2007;28:941-8.

15. Katashima T, Naruko T, Terasaki F, Fujita M, Otsuka K, Murakami S, Sato A, Hiroe M, Ikura Y, Ueda M, et al. Enhanced expression of the S100A8/A9 complex in acute myocardial infarction patients. Circ J. 2010;74:741-8.

16. Marinković G, Grauen Larsen H, Yndigegn T, Szabo IA, Mares RG, de Camp L, Weiland M, Tomas L, Goncalves I, Nilsson J, et al. Inhibition of pro-inflammatory myeloid cell responses by short-term S100A9 blockade improves cardiac function after myocardial infarction. Eur Heart J. 2019;40:271323. 
17. Sreejit G, Abdel-Latif A, Athmanathan B, Annabathula R, Dhyani A, Noothi SK, Quaife-Ryan GA, AlSharea A, Pernes G, Dragoljevic D, et al. Neutrophil-Derived S100A8/A9 Amplify Granulopoiesis After Myocardial Infarction. Circulation. 2020;141:1080-94.

18. Cui M, Fan M, Jing R, Wang $H$, Qin J, Sheng $H$, Wang $Y$, Wu X, Zhang L, Zhu J, et al. Cell-Free circulating DNA: a new biomarker for the acute coronary syndrome. Cardiology. 2013;124:76-84.

19. Helseth R, Shetelig C, Andersen G, Langseth MS, Limalanathan S, Opstad TB, Arnesen H, Hoffmann P, Eritsland J, Seljeflot I. Neutrophil extracellular trap components associate with infarct size, ventricular function, and clinical outcome in stemi. Mediators Inflamm. 2019;2019:7816491.

20. Weersink A, Kessel K, Tol M, Strijp J, Weiss J. Human Granulocytes express a 55-kDa lipopolysaccharide-binding protein on the cell surface that is identical to the Bactericidal/permeability-increasing protein. J Immunol. 1993;150:253-63.

21. Levy O. A neutrophil-derived anti-infective molecule: Bactericidal/permeability-increasing protein. Antimicrobial Agents Chemotherapy. 2000;44:2925-31.

22. Iwuji K, Larumbe-Zabala E, Bijlani S, Nugent K, Kanu A, Manning E, Solis X: Prevalence of Bactericidal/Permeability-Increasing Protein Autoantibodies in Cystic Fibrosis Patients: Systematic
Review and Meta-Analysis. Pediatric Allergy, Immunology, and Pulmonology 2019, 32:45-51.

23. Stoffel MP, Csernok E, Herzberg C, Johnson T, Carroll SF, Gross WL. Anti-neutrophil cytoplasmic antibodies (ANCA) directed against bactericidal/permeability increasing protein (BPI): a new seromarker for inflammatory bowel disease and associated disorders. Clinical Experimental Immunology. 2010;104:54-9.

24. Walmsley RS, Zhao MH, Hamilton MI, Brownlee A, Chapman P, Pounder RE, Wakefield AJ, Lockwood $\mathrm{CM}$. Antineutrophil cytoplasm autoantibodies against bactericidal/permeability-increasing protein in inflammatory bowel disease. Gut. 1997;40:105-9.

25. Schultz H, Csernok E, Sim. BPI-ANCA is found in reactive arthritis caused by Yersinia and Salmonella infection and recognise exclusively the C-terminal part of the BPI molecule. Scand J Rheumatol. 2000;29:226-31.

26. Chen $\mathrm{CZ}$, Ou CY, Wang RH, Lee $\mathrm{CH}$, Lin CC, Chang HY, Hsiue TR. The Role of Bactericidal/Permeability-Increasing Protein in Men with Chronic Obstructive Pulmonary Disease. Copd Journal of Chronic Obstructive Pulmonary Disease. 2012;9:197-202.

27. Chen XY, Qiu C. Serum BPI as a novel biomarker in asthma. Allergy Asthma Clinical Immunology. 2020;16:50.

28. Takeda S, Watanabe-Kusunoki K, Nakazawa D, Kusunoki Y, Nishio S, Atsumi T. The Pathogenicity of BPI-ANCA in a Patient With Systemic Vasculitis. Front Immunol. 2019;10:1334.

29. Zhao MH, Jones SJ, Lockwood CM. Bactericidal/permeability-increasing protein (BPI) is an important antigen for anti-neutrophil cytoplasmic autoantibodies (ANCA) in vasculitis. Clinical Experimental Immunology. 2010;99:49-56.

30. Alva V, Lupas, Andrei N. The TULIP superfamily of eukaryotic lipid-binding proteins as a mediator of lipid sensing and transport. Biochimica et Biophysica Acta Molecular cell biology of Lipids. 
2016;1861:913-23.

31. Gubern C, Vendrell J, Ricart W, FernáNdezreal JM. Natural antibiotics and insulin sensitivity the role of bactericidal/permeability-increasing protein. Diabetes. 2006;55:216.

32. Esteve E, Castro A, Moreno JM, Vendrell J, Ricart W, Fernández-Real JM. Circulating bactericidal/permeability-increasing protein (BPI) is associated with serum lipids and endothelial function. Thrombosis Haemostasis. 2010;103:780-7.

33. leijerveld B, Onno B, Wijten P, Cappadona S, Mcclellan EA, Polat AN, Raijmakers R, Sels JW, Colle L, Grasso S, et al. Deep proteome profiling of circulating granulocytes reveals bactericidal/permeabilityincreasing protein as a biomarker for severe atherosclerotic coronary stenosis. J Proteome Res. 2012;11:5235-44.

34. Schaft D, Toebes EAH, Haseman JR, Mayo KH, Griffıoen AW. Bactericidal/permeability-increasing protein (BPI) inhibits angiogenesis via induction of apoptosis in vascular endothelial cells. Blood. 2000;96:176-81.

35. Kristian T, Alpert JS, Jaffe AS, Chaitman B, Bax JJ, Morrow DA, White HD: Fourth Universal Definition of Myocardial Infarction (2018). Journal of the American College of Cardiology 2018, 72:S0735109718369419-.

36. Manesh R, PJ H, Dehmer JCG. J: ACC/AATS/AHA/ASE/ASNC/SCAI/SCCT/STS 2016 appropriate use criteria for coronary revascularization in patients with acute coronary syndromes: A report of the american college of cardiology appropriate use criteria task force, american association for thoraci. J Am Coll Cardiol. 2017;69:570-91.

37. Wijeysundera DN, Baber UB, John A, Bradley SM. Duration of dual antiplatelet therapy: A systematic review for the 2016 acc/aha guideline focused update on duration of dual antiplatelet therapy in patients with coronary artery disease: A report of the american college of cardiology/american heart associ. Circulation: An Official Journal of the American Heart Association 2016.

38. Gensini GG. A more meaningful scoring system for determining the severity of coronary heart disease. Am J Cardiol. 1983;51:606-6.

39. Rada B. Neutrophil extracellular traps. Methods in molecular biology. 2019;1982:517-28.

40. Kessenbrock K, Krumbholz M, Schönermarck U, Back W, Gross WL, Werb Z, Gröne HJ, Brinkmann V, Jenne DE. Netting neutrophils in autoimmune small-vessel vasculitis. Nat Med. 2009;15:623-5.

41. Fuchs TA, Hovinga JK, Schatzberg D, Wagner DD, Lammle B. Circulating DNA and myeloperoxidase indicate disease activity in patients with thrombotic microangiopathies. Blood. 2012;120:1157-64.

42. Eicher JD, Wakabayashi Y, Vitseva O, Esa N, Johnson AD. Characterization of the platelet transcriptome by RNA sequencing in patients with acute myocardial infarction. Platelets. 2016;27:230-9.

43. Zeller T, Seiffert M, Müller C, Scholz M, Schäffer A, Ojeda F, Drexel H, Mündlein A, Kleber ME, März W, et al. Genome-wide association analysis for severity of coronary artery disease using the gensini scoring system. Front Cardiovasc Med. 2017;20:57. 
44. Karaçağlar E, Akgün AN, Müderrisoğlu IH, Haberal M. Coronary Angiography for Follow-up of Heart Transplant Recipients: Usefulness of the Gensini Score. Exp Clin Transplant. 2020;18:99-104.

45. Silvestre-Roig C, Braster Q, Ortega-Gomez A, Soehnlein O. Neutrophils as regulators of cardiovascular inflammation. Nature Reviews Cardiology.

46. Alva V, Lupas AN. The TULIP superfamily of eukaryotic lipid-binding proteins as a mediator of lipid sensing and transport. BBA - Molecular Cell Biology of Lipids. 2016;1861:913-23.

47. Wong LH, Levine TP. Tubular lipid binding proteins (TULIPs) growing everywhere. Elsevier Sponsored Documents. 2017;1864:1439-49.

48. Carestia A, Kaufman T, Rivadeneyra L, Landoni V, Pozner RG, Negrotto S, D’Atri LP, Gómez RM, Schattner M. Mediators and molecular pathways involved in the regulation of neutrophil extracellular trap formation mediated by activated platelets. J Leukoc Biol. 2016;99:153-62.

49. Linge P, Fortin PR, Lood C, Bengtsson AA, Boilard E. The non-haemostatic role of platelets in systemic lupus erythematosus. Nat Rev Rheumatol. 2018;14:195-213.

50. Braedon MD, Rachelle PD, Seok-Joo K, Mandy T, Charles TE, Elzbieta K, Craig NJ. Platelets and neutrophil extracellular traps collaborate to promote intravascular coagulation during sepsis in mice. Blood: The Journal of the American Society of Hematology. 2017;129:1357-67.

51. Fuchs TA, Brill A, Duerschmied D, Schatzberg D, Monestier M, Myers DD Jr, Wrobleski SK, Wakefield TW, Hartwig JH, Wagner DD. Extracellular DNA traps promote thrombosis. Proc Natl Acad Sci U S A. 2010;107:15880-5.

52. Schrottmaier WC, Mussbacher M, Salzmann M, Assinger A. Platelet-leukocyte interplay during vascular disease. Atherosclerosis 2020, 307.

53. Moschonas IC, Tselepis AD. The pathway of neutrophil extracellular traps towards atherosclerosis and thrombosis. Atherosclerosis. 2019;288:9-16.

54. Silvain J, Collet JP, Nagaswami C, Beygui F, Edmondson KE, Bellemain-Appaix A, Cayla G, Pena A, Brugier $\mathrm{D}$, Barthelemy $\mathrm{O}$, et al. Composition of coronary thrombus in acute myocardial infarction. $\mathrm{J}$ Am Coll Cardiol. 2011;57:1359-67.

55. Miguel JA, Tobias KN. AF: Circulating extracellular DNA: Cause or consequence of thrombosis? Seminars in Thrombosis Hemostasis. 2017;43:553-61.

56. Demyanets S, Stojkovic S, Mauracher LM, Kopp CW, Wojta J, Thaler J, Panzer S, Gremmel T. Surrogate markers of neutrophil extracellular trap formation are associated with ischemic outcomes and platelet activation after peripheral angioplasty and stenting. J Clin Med 2020, 9.

57. Borissoff JI, Joosen IA, Versteylen MO, Brill A, Fuchs TA, Savchenko AS, Gallant M, Martinod K, Ten Cate $\mathrm{H}$, Hofstra L. Elevated levels of circulating DNA and chromatin are independently associated with severe coronary atherosclerosis and a prothrombotic state. Arteriosclerosis Thrombosis Vascular Biology. 2013;33:2032-40.

58. Urban CF, Ermert D, Schmid M. Neutrophil extracellular traps contain calprotectin, a cytosolic protein complex involved in host defense against candida albicans. Plos Pathogens. 2009;5:e1000639. 
59. Miyamoto S, Ueda M, Ikemoto M, Naruko T, Itoh A, Tamaki S, Nohara R, Terasaki F, Sasayama S, Fujita M. Increased serum levels and expression of S100A8/A9 complex in infiltrated neutrophils in atherosclerotic plaque of unstable angina. Heart. 2008;94:1002-7.

60. Putten R, Glatz J, Hermens WT. Plasma markers of activated hemostasis in the early diagnosis of acute coronary syndromes. Clin Chim Acta. 2006;371:37-54.

\section{Figures}

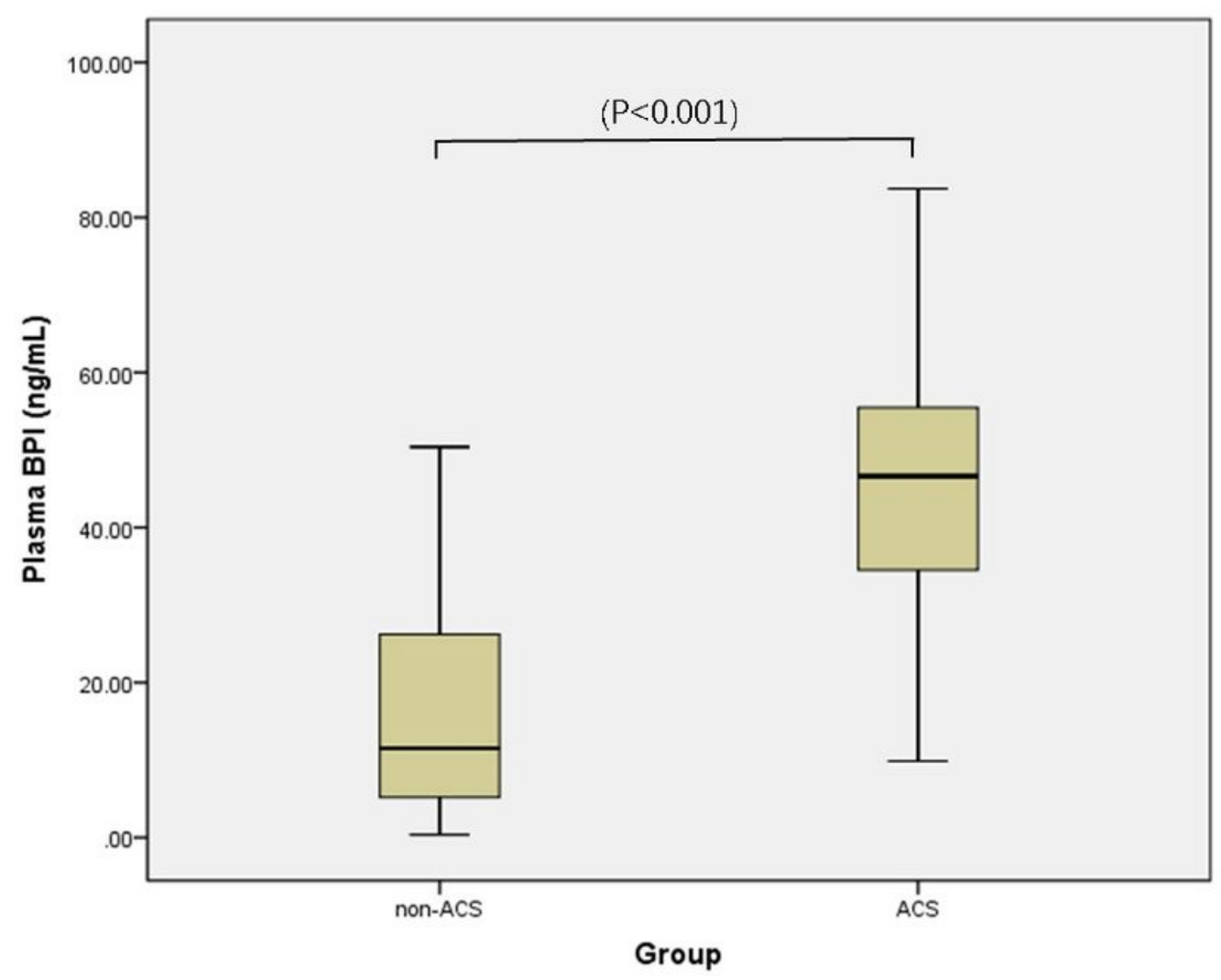

Figure 1

Comparison of plasma BPI levels between non-ACS and ACS groups. 

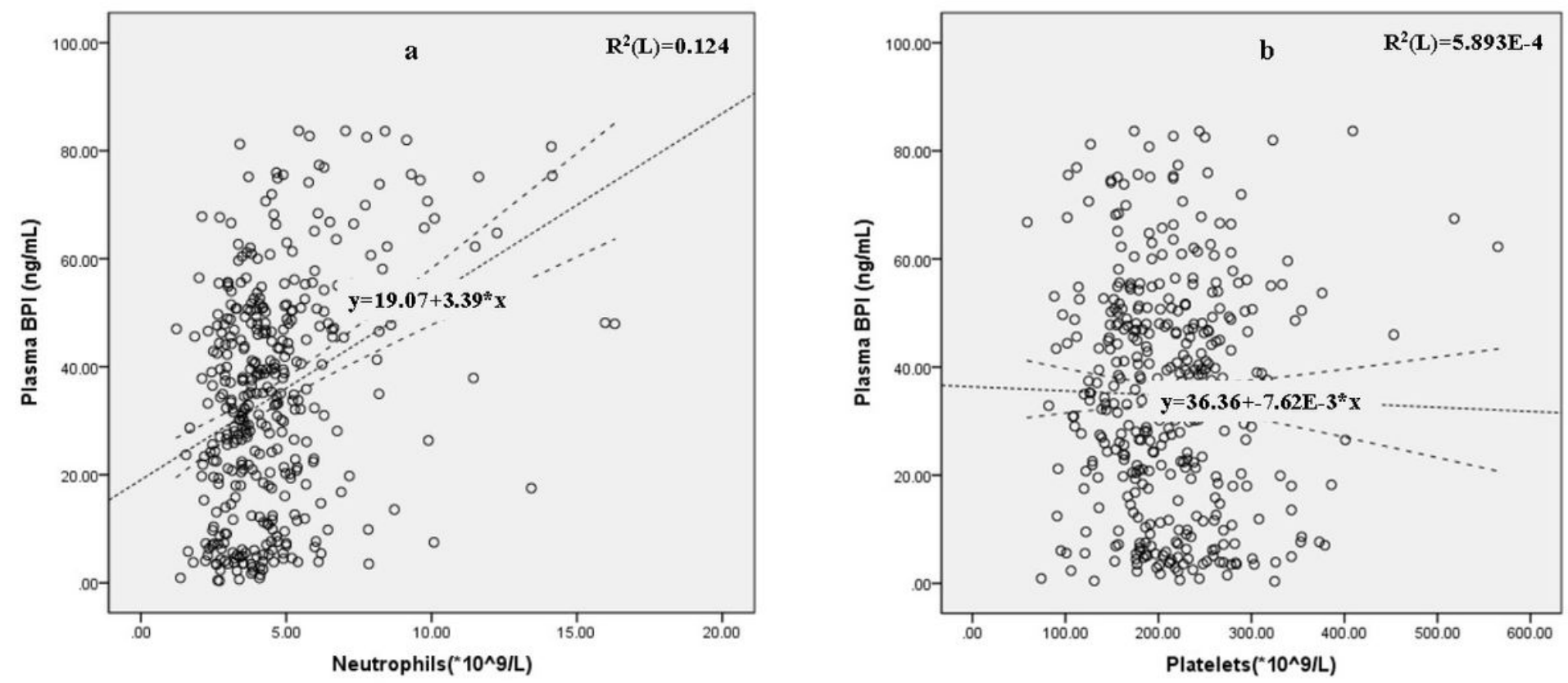

\section{Figure 2}

Correlations of plasma BPI levels with blood neutrophil and platelet counts.
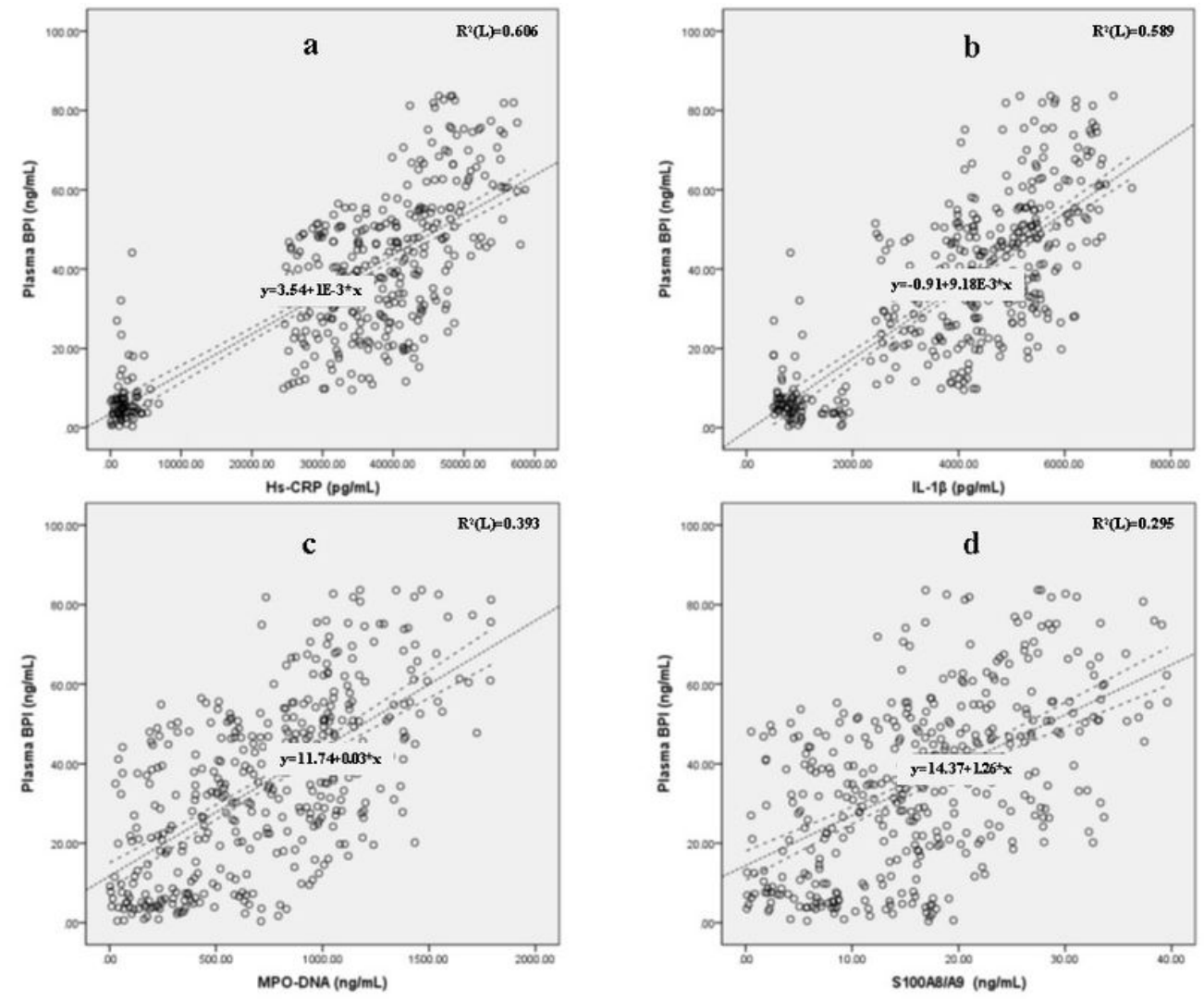

Figure 3 
Correlations of plasma BPI levels with the levels of hs-CRP, IL-1ß, MPO-DNA, and S100A8/A9.
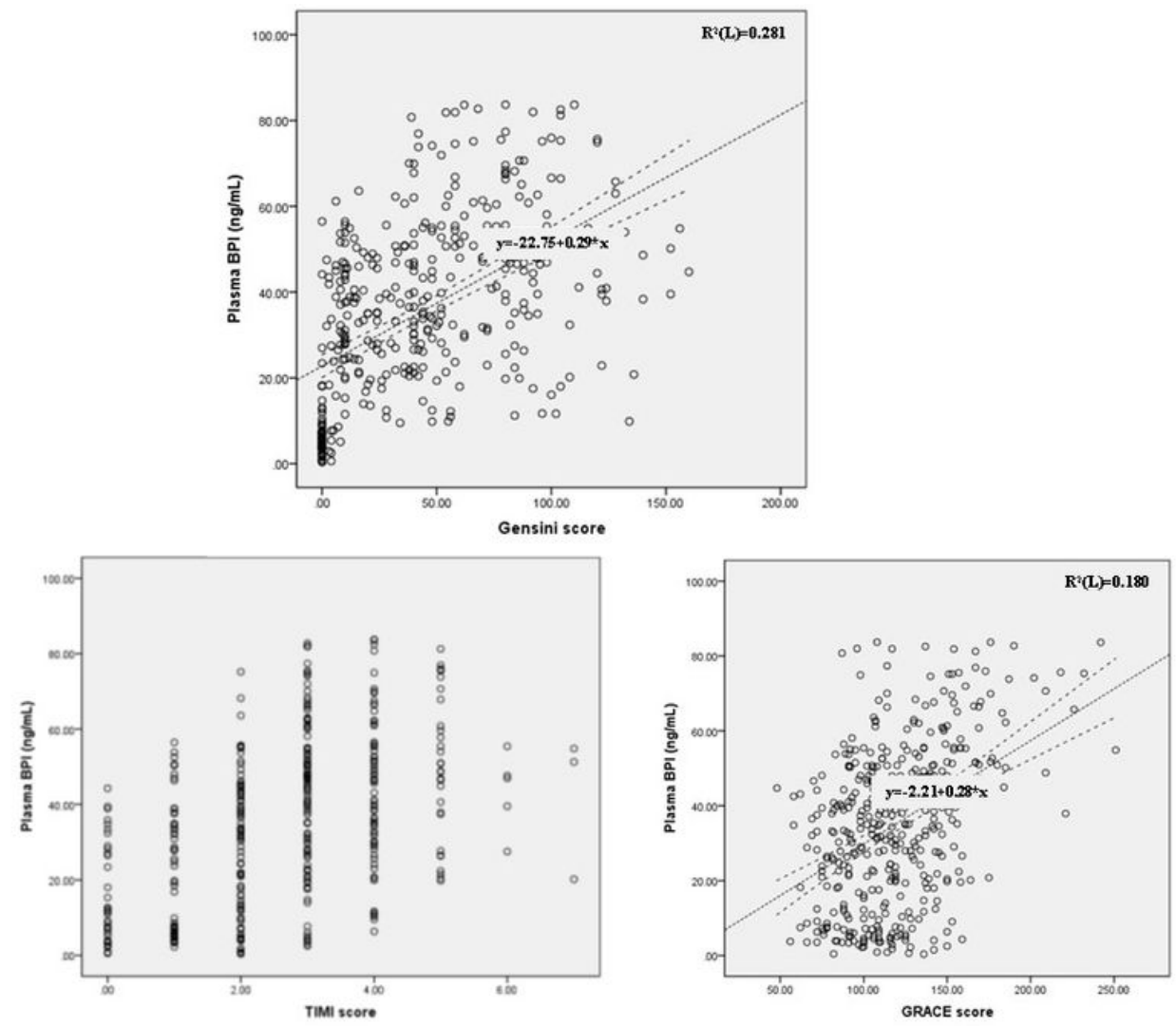

\section{Figure 4}

Correlations of plasma BPI levels with the TIMI, GRACE, and Gensini scores.

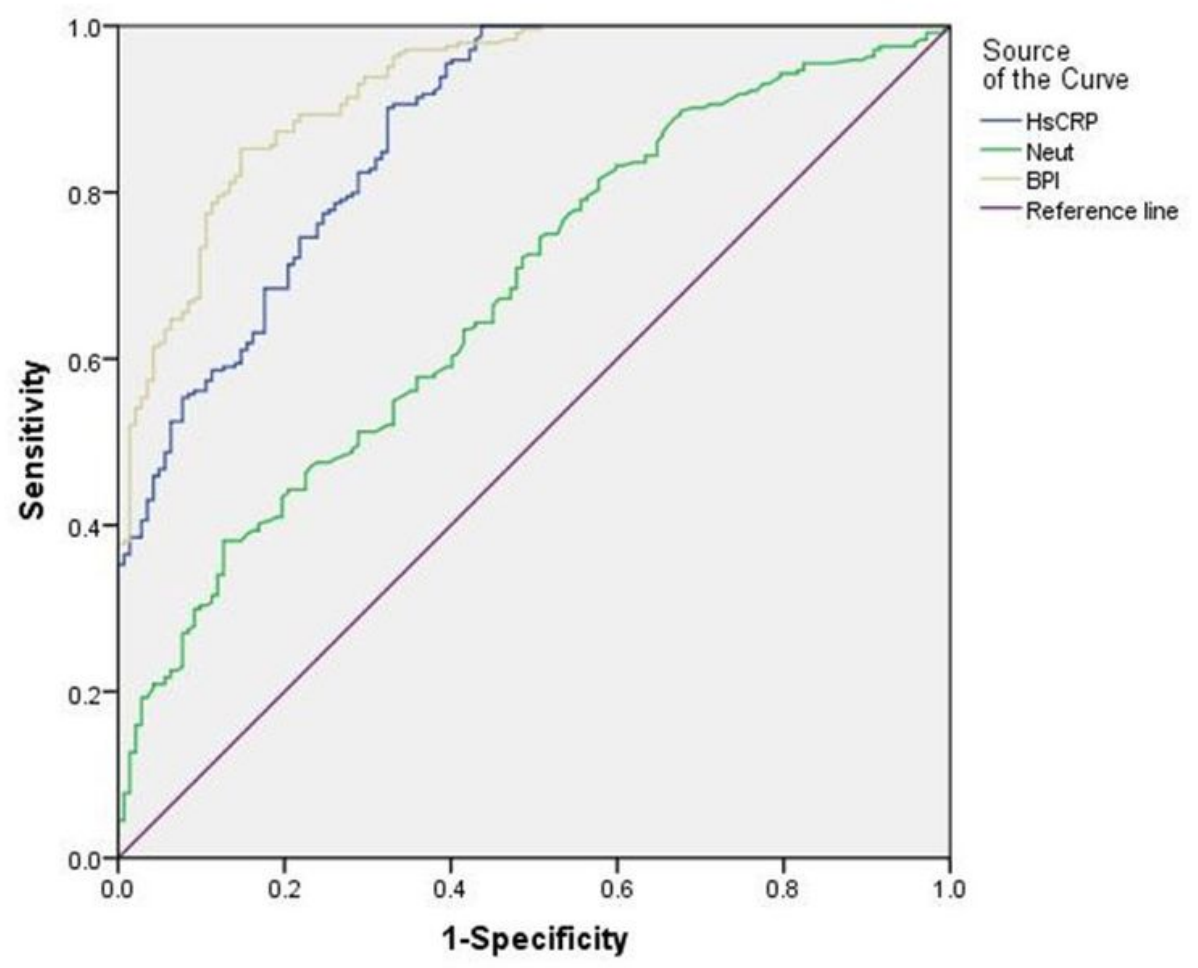


Figure 5

ROC analysis of the diagnostic efficacy of plasma BPI, Hs-CRP, and blood neutrophil counts for ACS.

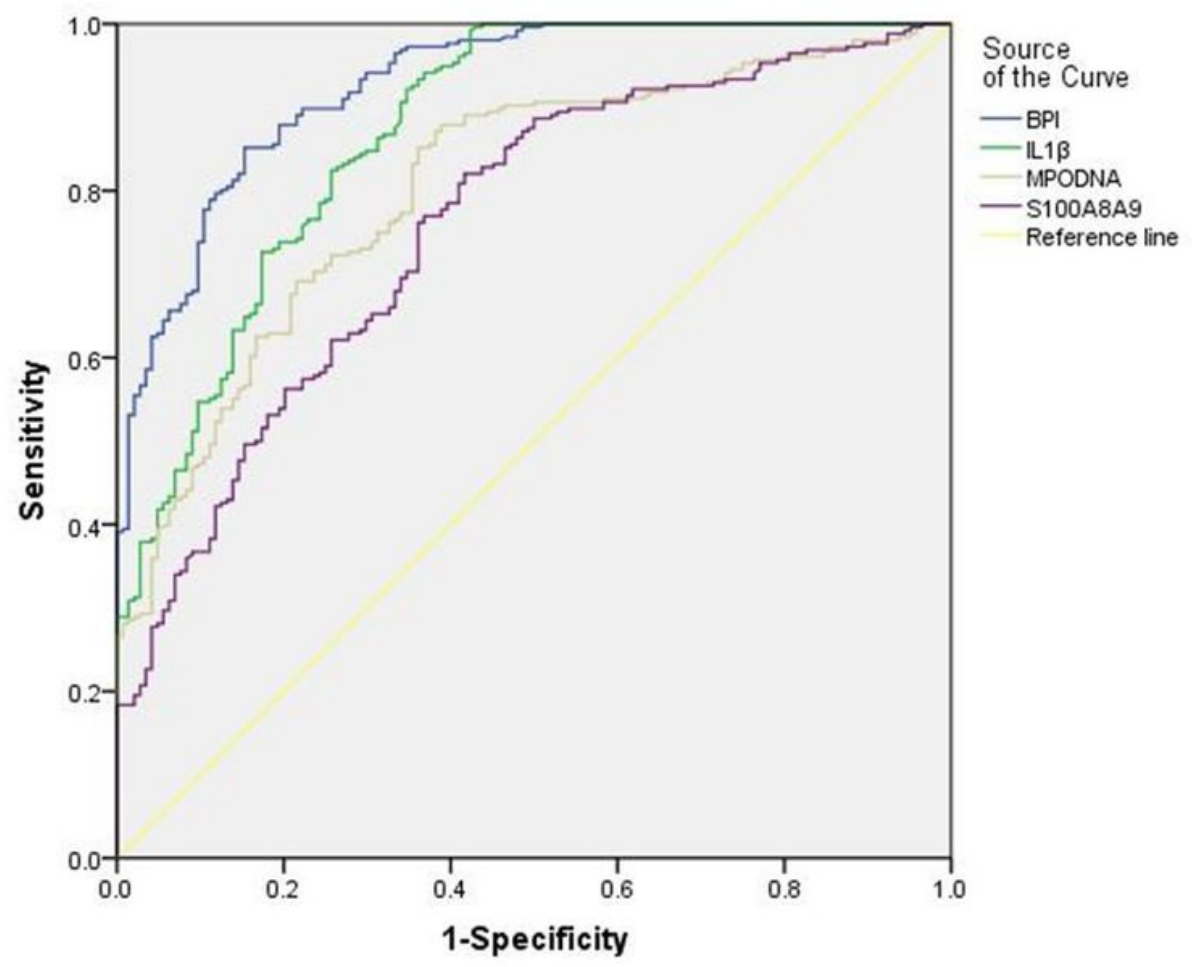

Figure 6

ROC analysis of the diagnostic efficacy of plasma BPI, IL-13, MPO-DNA, and S100A8/A9 for ACS. 


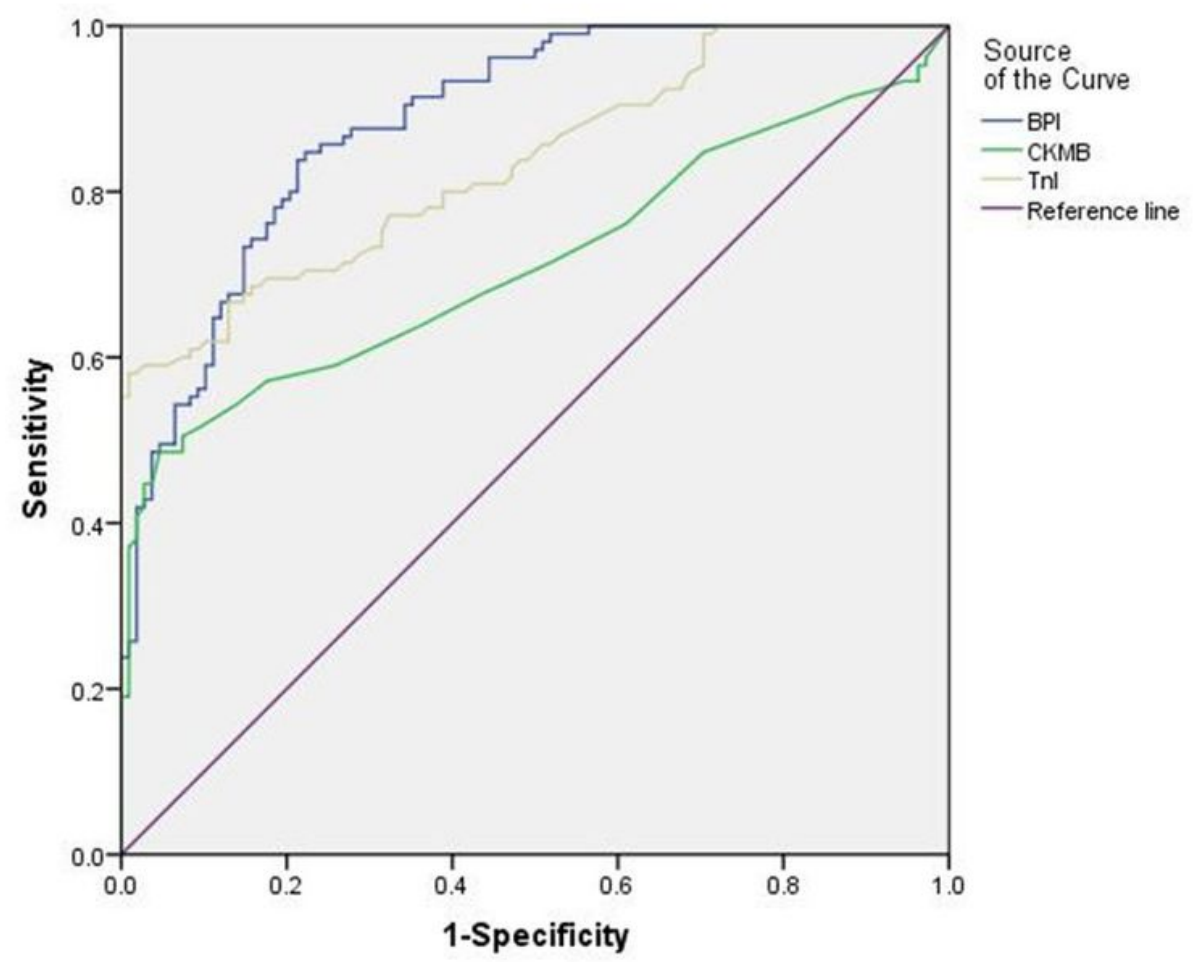

Figure 7

ROC analysis of the diagnostic efficacy of plasma BPI, CK-MB, and Tnl for MI. 